\title{
Differences in Black and White Perceptions regarding Addressing Racial Inequality in the Workplace
}

\author{
Richard Lewis \\ University of Texas at San Antonio, San Antonio, TX, USA \\ Email: richardlewis12@sbcglobal.net
}

How to cite this paper: Lewis, R. (2017) Differences in Black and White Perceptions regarding Addressing Racial Inequality in the Workplace. Open Access Library Journal, 4: e4199.

https://doi.org/10.4236/oalib.1104199

Received: November 26, 2017

Accepted: December 16, 2017

Published: December 19, 2017

Copyright $\odot 2017$ by author and Open Access Library Inc.

This work is licensed under the Creative Commons Attribution International License (CC BY 4.0).

http://creativecommons.org/licenses/by/4.0/

\begin{abstract}
This research effort explores the difference in black and white perceptions concerning racial inequality in the contemporary American workplace. Age, educational attainment, personal income, political views, gender, and work status were used to delineate interactive effects on inequality perceptions. Conflict Theory was used for framing the social inequality process. Historically, conflict theorists have viewed relationships between groups as being characterized by competition or conflict resulting in social inequality. The data used to examine perceptions of racial inequality were obtained from the 2016 General Social Survey. This research effort found that blacks and whites demonstrated very different perceptions regarding workplace racial inequality. Generally, blacks believed there are significant barriers to equal treatment while whites felt that no remedies are necessary for ensuring minority participation in the workplace. The findings showed black and white respondents had very different perceptions for addressing workplace inequality. Black individuals tended to view preferential hiring and promotion as a way to successfully reduce racial inequality. Whites, on the other hand, illustrated the opposite viewpoint by overwhelmingly not supporting preferential treatment as an organizational tool for dealing with workplace racial inequality.
\end{abstract}

\section{Subject Areas}

Sociology

\section{Keywords}

Differential Treatment, Inequality, Institutional Barriers, Racial

Discrimination, Racial Groups, Workplace Issues 


\section{Introduction}

Demographic transition is an extraordinary phenomenon in the $21^{\text {st }}$ Century United States. The racial, gender, and social class landscape is rapidly changing. Shortly after the United States Census was completed in 2000, Latinos became the largest racial minority group surpassing Black Americans. It is projected by 2050, Asian Americans will experience a 300\% increase in population size from 1990. Women will continue to outnumber men. The upper-class and under-class are dramatically increasing while the middle-class is shrinking. These facts provide a brief snapshot of the ongoing transformation within the American society [1].

Changes in key demographic characteristics will significantly impact the workplace resulting in challenges for those leading government, non-profit and private organizations. The future workforce will increasingly be composed of individuals from historically disenfranchised racial, gender, and socio-economic groups. All other important economic, political, educational, and technological initiatives will be impacted by a diverse American society as well. Differential and restricted access within organizations based on race, gender, or social class thereby preserving aspects of privilege could contribute to continued discrimination and inequality in the contemporary workplace.

Addressing demographic transition and ensuring the legal components of equal access are two of the most critical issues facing the United States. Creating discrimination-free workplaces which offer professional growth for employees across various dimensions such as race, gender, and socioeconomic status will continue to be an organizational challenge [2] [3] [4].

The purpose of this research effort was to explore the perceptions of how racial inequality in the contemporary American workplace should be addressed. This endeavor focused on two aspects of racial discrimination by comparing how black and white individuals perceive institutional approaches linked to reducing inequality. One approach consisted of reducing racial prejudice and discrimination through the use of affirmative action policy. The other involved blacks working themselves up the workplace ladder as other minorities have done historically, thereby reducing inequality. Additionally, age, educational attainment, personal income, political views, gender, and work status were used to delineate interactive effects on the perceptions of the two approaches connected to workplace racial inequality.

\section{Relevant Literature and Theory Application}

\subsection{Historical Account of Black-White Relations}

Dominant-subordinate relationships between White Americans and Black Americans were established in the United States through the institution of slavery. During the Colonial era, slavery for Black Americans became a lifetime experience around 1660 and it codified racial segregation [5] [6]. One of the major 
outcomes of the Civil War was the abolishment of slavery in 1865. From 1866 through 1877, the Reconstruction period saw major social changes as racial inequality became illegal and blacks became American citizens. Historically, the dilemma for blacks has always been whether the groups should pursue the policy of segregation or integration. For example, in the late 1800s, Booker T. Washington advocated adjusting to a segregated America while W. E. B. DuBois discussed full inclusion. This debate continues and encompasses most segments of contemporary American society. Related to the tension between a policy of segregation and integration is the status of racial inequality. Most Civil Rights proponents suggest that full inclusion (integration) fosters the mitigation of racial inequality for Black Americans [7]. This is especially related to treatment in the workplace.

\subsection{Perceptions and Social Reality}

A society's culture plays a vital role in creating perceptions of reality among its members. Sociologists argue that social reality is the perceptions of social behavior and conditions which individuals harbor. Therefore, individuals react to their perceptions as if they are real. Merton described this as a self-fulfilling prophesy [8]. For example, in 2017 shortly after Hurricane Harvey devastated Southeast Texas, individuals took to social media and spread a rumor that San Antonio, Texas would have gasoline shortages. The resulting behavior was a run on gasoline that left the city without adequate gasoline availability for several weeks. The hoarding behavior created the gasoline shortage that was projected on social media.

Perceptions of reality often produce standardized images of individuals, groups, and organizations. These are often referred to as stereotypes [3]. Racial stereotypes are a result of unchallenged or unfounded perceptions. These can become real in their consequences [9]. Images of lazy racial minorities or rich, white conservative individuals become pervasive. Contemporary media enhances, not maliciously, the overgeneralizing images.

Perceptions are only partially reflective of social reality. They can create disconnects and distortions of reality. All of the defining social reality components are embedded in culture. Differences between ideology and reality can be found within society, often between social groups. In the United States, perceptions of racial inequality provide an example of this paradox. The ideal is that every individual enjoys racial equality as reflected in the American value system. The reality is that there are institutional impediments relative to racial equality resulting in a racially stratified society [10].

\subsection{Theoretical Perspective}

Group dynamics frames the understanding racial inequality created and maintained through discrimination. A group can be defined as a collection of people, based on an attribute, who interact with one another and have a certain feeling 
of unity [6]. Every society is comprised of individuals who simultaneously have membership in a number of groups. Because most societies are composed of a variety of groups, diversity is multi-dimensional and is a very complex notion. There is inequality between the attributes that delineate the differences between groups. Society determines what diversity dimensions are important at any given point in time [3]. The ability to assign individuals to a group or a number of groups is a critical factor. Social attributes, either physically tangible or socially-created, are used to identify who is in a group and who is not a group member. Individuals must agree on the differences and importance associated with them. As a result, group membership creates a social perception of an in-group versus an out-group orientation between people. Social attributes are major components through which individual as well as group interactions occur [8]. Access to power, authority, and resources is differential. In most societies around the world, groups and the individuals comprising them do not have the same access to societal elements of power and influence. As a result, one grouping is considered dominant and the other groupings are characterized as subordinate [6]. Merton has used the terms in-groups and out-groups to illustrate differential power access issues between groups [8].

The conflict theoretical perspective is appropriate in framing the social inequality process. Historically, conflict theorists have viewed relationships between groups as being characterized by competition or conflict resulting in social inequality [11]. Ultimately, the social group garnering more access to power, authority, and resources becomes the dominant group in society. Institutions become stratified based on how society socially defines groups; differential treatment (discrimination) is used as a strategy by the dominant group to maintain its collective advantage. In contemporary American society, this dynamic is illustrated by inequality between subcomponents comprising race, gender, age, and social class. Dahrendorf would describe the resulting group inequality as a product of interrelations between competing groups. He uses the term inter-coordinated associations (ICAs) to delineate groups arranged based on power and resource dimensions [12].

Social closure plays an integral role in maintaining inequality between social groups. This is especially true for differences between racial groups [13]. Social closure is basically a process that creates boundaries, identities, and structures to monopolize scarce resources for one's own group while excluding out-group members [14]. Therefore, participation in areas of society may be limited to certain groups initiating and maintaining inequality. Social closure results in racial inequality in the United States and discrimination is a sub-process that stimulates differential access in a variety of institutions within American society [15]. Tension related to social closure has created a paradox relative to equal opportunity. American values espouse a society, from a philosophical perspective, that is color-blind based on race. In reality, racial and ethnic differences are important components in the stratification found within the United States. For instance, White Americans have higher personal income, higher personal wealth, 
and higher educational attainment in comparison to racial minority groups. The gaps between groups have remained relatively unchanged since 1970 . The lone exception is the income and educational gains of Asian Americans [1]. Based on the conflict perspective and its emphasis on social inequality, the following research hypotheses were developed for analysis:

$\mathrm{H}_{1}$ : White and black individuals perceive affirmative action policy differently. Whites tend to view the policy less favorably in comparison to their black counterparts.

$\mathrm{H}_{2}$ : White and black individuals perceive using the minority model of working one's way up in the workplace to offset discrimination differently. Whites are more likely to believe that working one's way up is appropriate for minimizing discrimination in comparison to their black counterparts.

\section{Research Methodology}

The sample used to examine perceptions of racial inequality in the workplace were obtained from the General Social Survey (GSS) conducted on the adult United States population in 2016. It is an area-probability sample utilizing a national sampling frame for an equal-probability multi-stage cluster sample of housing units for the entire United States. These data provide a great deal of information on core demographic, behavioral, and attitudinal questions including those related to racial inequality [16]. Statistical analyses were conducted using the IBM Statistical Package for the Social Sciences (SPSS), version 24.

This study employed multiple logistic regression analysis utilizing a number of research variables. The sociological theory discussed earlier provided the foundation for the statistical analysis.

Dependent Variables. The database included two variables related to perceptions of racial inequality in the workplace. These were used as dependent variables and how respondents were queried is displayed below.

Question 1. "Are you for or against preferential hiring and promotion of blacks?"

Question 2. "Many other minorities overcame prejudice and worked their way up. Blacks should do the same without special favors."

The response categories for preferential hiring and promotion are $1=$ strongly support preference, $2=$ support preference, $3=$ oppose preference, and $4=$ strongly oppose preference. The response categories for overcoming workplace prejudice are 1 = agree strongly, 2 = agree somewhat, $3=$ neither agree nor disagree, 4 = disagree somewhat, $5=$ disagree strongly.

Independent Variables. The analysis considered seven possible predictors to one's attitudes regarding racial inequality in the workplace. These include race (dummied into two categories; 0 = White, $1=$ Black), gender (dummied into two categories; $0=$ men, $1=$ women $)$, political views $(1=$ liberal, $2=$ moderate, $3=$ conservative), labor force status ( 1 = working full-time, 2 = working part-time, 3 = not working), age (spanning 18 - 89 years of age), highest years of formal education completed (ranging from 0 - 20 years), and annual personal income. 
Two multiple binary logistic regression models, guided by our theoretical underpinnings, were created for responses linked to perceptions of racial inequality in the workplace. It should be noted that the two dependent (response) variables were measured as categorical variables. Support for preferential hiring and promotion of blacks was collapsed into two categories (not support $=0$ and support $=$ 1). Blacks working their way up was recoded into two categories as well (agree = 0 and disagree $=1$ ). Making these binary variables facilitated the predictive nature of logistic regression analysis.

\section{Study Findings}

\subsection{Sample Description}

The standard error of the mean (SEM) was examined for the variables used in this research effort. For each variable, it was concluded that the SEM was small enough to conclude the variables were acceptable estimates of the population parameters (see Table 1). For gender, approximately $56 \%$ of were female. The average age of the respondent was 49 years with the average educational attainment at nearly 14 years of formal schooling. The average annual personal income was approximately $\$ 23,800$. About $60 \%$ were currently working and most indicated that the workplace was comprised mostly of white colleagues. Lastly, $37 \%$ stated their political views were moderate and another $34 \%$ said they were conservative (see Table 1).

Race was employed as one of the most important independent variables. About $81 \%$ of the sample was white and the remaining $19 \%$ was black. This distribution over-represented both racial groups slightly in comparison to their overall composition of the United States population. This posed no methodological challenges with respect to the statistical analysis utilized in this study.

The two racial inequality perception variables illustrate interesting distributions. Approximately $76 \%$ of the respondents said they were against preferential hiring and promotion of blacks. Additionally, nearly $63 \%$ indicated they agreed that blacks should work their way up without special favors (see Table 1).

The bivariate chi-square analysis shows that racial background impacts political viewpoints, perceptions of hiring and promotion, and perceptions of working up without special favors. For political views, the modal response for both black and white respondents was moderate. However, blacks tended to say they were liberal and whites tended to say they were conservative. Regarding preferential hiring and promotion, about $82 \%$ of whites opposed this policy in comparison to $59 \%$ of blacks. It was found that $66 \%$ of white respondents and $48 \%$ of black respondents felt that blacks should work themselves up without special favors. Lastly, there was a difference found relative to work status. The majority of both groups were working either full-time or part-time (see Table 2).

\subsection{Perceptions of Addressing Racial Inequality in the Workplace}

Binary logistic regression analysis was used to determine multiple variable 
Table 1. Summary of study predictor variables associated with perceptions of ways to reduce racial inequality in the workplace, 2016.

\begin{tabular}{|c|c|c|c|c|c|}
\hline & Mean & $\begin{array}{l}\text { Standard } \\
\text { Deviation }\end{array}$ & $\begin{array}{l}\text { Standard } \\
\text { Error of } \\
\text { the Mean }\end{array}$ & Percent & Number \\
\hline Race & & & 0.01 & & \\
\hline White & & & & 81.1 & 2100 \\
\hline Black & & & & 18.9 & 490 \\
\hline Gender & & & 0.01 & & \\
\hline Male & & & & 44.7 & 1158 \\
\hline Female & & & & 55.3 & 1432 \\
\hline Political Views & & & 0.02 & & \\
\hline Liberal & & & & 28.4 & 709 \\
\hline Moderate & & & & 37.3 & 932 \\
\hline Conservative & & & & 34.3 & 858 \\
\hline Labor Force Status & & & 0.02 & & \\
\hline Working Full-time & & & & 46.2 & 1195 \\
\hline Working Part-time & & & & 11.6 & 300 \\
\hline Not working & & & & 42.2 & 1093 \\
\hline Age & 49.48 & 17.40 & 0.34 & & 2559 \\
\hline $\begin{array}{l}\text { Educational } \\
\text { Attainment }\end{array}$ & 13.82 & 2.87 & 0.06 & & 2582 \\
\hline Personal Income & $\$ 23,665.67$ & $\$ 28,562.47$ & $\$ 742.20$ & & 1481 \\
\hline $\begin{array}{l}\text { “Are you for or } \\
\text { against preferential } \\
\text { hiring and } \\
\text { promotion of } \\
\text { blacks?" }\end{array}$ & & & 0.025 & & \\
\hline Strongly support & & & & 14.1 & 227 \\
\hline Support & & & & 8.3 & 134 \\
\hline Oppose & & & & 30.6 & 492 \\
\hline Strongly Oppose & & & & 47.0 & 755 \\
\hline $\begin{array}{l}\text { "Blacks should work } \\
\text { their way up without } \\
\text { special favors." }\end{array}$ & & & 0.031 & & \\
\hline Strongly agree & & & & 36.3 & 611 \\
\hline Agree somewhat & & & & 25.9 & 436 \\
\hline $\begin{array}{l}\text { Neither agree } \\
\text { or disagree }\end{array}$ & & & & 15.9 & 267 \\
\hline Disagree somewhat & & & & 10.9 & 183 \\
\hline Strongly disagree & & & & 10.9 & 184 \\
\hline
\end{tabular}

influence on hiring preference and ways minorities work their way up the employment ladder. Regarding preferential hiring and promotion, it was found that 
Table 2. Political views, work status, perceptions of preferential hiring and promotion, and working way up without special favors, 2016.

\begin{tabular}{|c|c|c|c|}
\hline Item & White \% & Black \% & Chi-Square \\
\hline Political Views & & & $23.75^{\star * *}$ \\
\hline Liberal & 27.8 & 30.7 & \\
\hline Moderate & 35.7 & 44.4 & \\
\hline Conservative & 36.5 & 24.9 & \\
\hline Total & $100.0(2033)$ & $100.0(466)$ & \\
\hline Labor Force Status & & & $0.47^{\mathrm{ns}}$ \\
\hline Working Full-time & 46.0 & 47.0 & \\
\hline Working Part-time & 11.5 & 12.1 & \\
\hline Not working & 42.5 & 40.9 & \\
\hline Total & $100.0(2099)$ & $100.0(489)$ & \\
\hline \multicolumn{4}{|l|}{$\begin{array}{l}\text { "Are you for or against } \\
\text { preferential hiring and } \\
\text { promotion of blacks?" }\end{array}$} \\
\hline Strongly support & 10.5 & 29.6 & $91.46^{* * *}$ \\
\hline Support & 7.5 & 11.8 & \\
\hline Oppose & 31.2 & 28.0 & \\
\hline Strongly Oppose & 50.8 & 30.6 & \\
\hline Total & $100.0(1304)$ & $100.0(304)$ & \\
\hline \multicolumn{4}{|l|}{$\begin{array}{l}\text { "Blacks should work their way } \\
\text { up without special favors." }\end{array}$} \\
\hline Strongly agree & 38.1 & 28.6 & $62.18^{* * *}$ \\
\hline Agree somewhat & 27.4 & 19.6 & \\
\hline Neither agree or disagree & 15.7 & 16.7 & \\
\hline Disagree somewhat & 10.6 & 12.2 & \\
\hline Strongly disagree & 8.2 & 22.8 & \\
\hline Total & $100.0(1370)$ & $100.0(311)$ & \\
\hline
\end{tabular}

ns, not statistically significant, ${ }^{*} p<0.05,{ }^{* *} p<0.01,{ }^{* * *} p<0.001$.

race, political views, and educational attainment influenced preferential hiring and promotion. Race had the strongest influence. Blacks were almost two times more likely to support preferential hiring/promotion in comparison to whites. Political conservatives were about two times more likely to not support preferential hiring/promotion policies in comparison to non-conservatives. Individuals with higher educational attainment were more likely to support preferential hiring/promotion policies. It should be noted that gender, work status, age, and personal income were not related to these perceptions of addressing racial inequality in the workplace. The regression model explained approximately $13 \%$ of the variation in attitudes toward preferential hiring and promotion of blacks (see Table 3).

The perception of blacks working their way up like other minorities was 
Table 3. Summary of binary logistic regression of selected independent variables on preferential hiring and promotion and blacks working their way Up Like other minorities, 2016.

\begin{tabular}{ccccc}
\hline & \multicolumn{2}{c}{ Preferential Hiring } & \multicolumn{2}{c}{ Working Way Up } \\
\hline Variables in Model & B & Exp (B) & B & Exp (B) \\
\hline Race & $-1.381^{* * *}$ & 0.251 & $0.967^{* * *}$ & 2.630 \\
Gender & -0.079 & 0.024 & -0.014 & 0.986 \\
Conservative & $0.822^{* * *}$ & 2.272 & $-1.039^{* * *}$ & 0.354 \\
Work Status & 0.309 & 1.363 & -0.263 & 0.769 \\
Age & -0.011 & 0.989 & -0.010 & 0.990 \\
Educational Attainment & $-0.087^{* *}$ & 0.917 & $0.217^{\star * *}$ & 1.243 \\
Personal Income & 0.000 & 1.000 & 0.000 & 1.000 \\
Constant & $2.838^{* * *}$ & 17.074 & $-2.566^{* * *}$ & 0.077 \\
Hosmer/Lemeshow Test $\left(X^{2}\right)$ & 9.668 & & 8.712 & \\
Nagelkerke R Square & 0.130 & & 0.178 & \\
\hline
\end{tabular}

${ }^{*} p<0.05,{ }^{* *} p<0.01$, and ${ }^{* *} p<0.001$.

impacted by three dependent variables. White respondents were $21 / 2$ times more likely than blacks to agree that blacks should work their way up the employment ladder like other minorities. In addition, respondents who labeled themselves as political conservatives were 1 1/2 times more likely to feel that blacks should follow the employment process of other minorities when compared to non-conservative respondents. Individuals with higher education were more likely to disagree with blacks should work their way up the employment ladder similar to other minorities. It should be noted that gender, work status, age, and personal income were not associated with this dependent variable. The overall regression model explained approximately $18 \%$ of the variation in perceptions of blacks working their way up the employment ladder (see Table 3 ).

\section{Study Conclusions}

This research effort found that blacks and whites demonstrated very different perceptions regarding workplace racial inequality. Generally, blacks believed there are significant barriers to equal treatment while whites felt that no remedies are necessary for ensuring minority participation in the workplace. Based on the statistical analysis, the research hypothesis stating white and black individuals perceive affirmative action policy differently was accepted. The second research hypothesis positing white and black individuals perceive using the minority model of working one's way up in the workplace to offset discrimination differently was accepted as well.

The findings showed black and white respondents had very different perceptions for addressing workplace inequality. Black individuals tended to view preferential hiring and promotion as a way to successfully reduce racial inequality. Whites, on the other hand, illustrated the opposite viewpoint by overwhelmingly 
not supporting preferential treatment as an organizational tool to combat workplace racial inequality. Being politically conservative was also related to not supporting these types of policy (white respondents were more conservative than their black counterparts).

Perceptions related to the historical model used by other minorities to improve their employment participation is associated with race and political viewpoints. Whites and those politically conservative felt that blacks should use the same model and, as a result, racial inequality will be mitigated. Higher educated individuals seemed to be less supportive of this historical model as a vehicle for blacks in contemporary American society.

As emphasized earlier, the two theoretical hypotheses were supported by the research findings. The substantial differences in perceptions of workplace racial inequality and how to address it are indicative of a widening gulf between black and white Americans. The findings are indirect indicators of a racial divide within the United States which was strengthened by recent political polarization dating back to 2008. As a result, racial groups do not share a similar viewpoint of society. Rather, they appear to develop and employ differential perceptions of American society and racial differences continue to be challenge throughout the institutional fabric of the United States.

\section{References}

[1] United States Bureau of the Census (2015) General Characteristics of the Population.

[2] Hurtado, S. and Dey, E.L. (1997) Achieving the Goals of Multicultralism and Diversity. In: Peterson, M.W., Dill, D.D. and Mets, L.A., Eds., Planning and Management for a Changing Environment. Jossey-Bass, San Franscisco, 405-431.

[3] Lewis, R. (2002) The Diversity Challenge: A Systematic Approach for Addressing Difference in Organizations. Journal of the Texas Association for Marriage and Family Therapy, 7, 63-70.

[4] Tierney, W.G. (1997) Organizational Socialization in Higher Education. The Journal of Higher Education, 68, 1-16. https://doi.org/10.1080/00221546.1997.11778975

[5] Geschwender, J.A. (1978) Racial Stratification in America. W. C. Brown, Dubuque, IA.

[6] Yancey, G. and Lewis, R.Jr. (2008) Interracial Families: Current Concepts and Controversies. Routledge Press (Taylor and Francis subsidiary), New York.

[7] Marger, M. (2012) Race and Ethnic Relations: American and Global Perspectives. Ninth Edition, Wadsworth, Belmont, California.

[8] Merton, R. (1968) Social Theory and Social Structure. Free Press, New York.

[9] Guess, T.J. (2006) The Social Construction of Whiteness: Racism by Intent, Racism by Consequences. Critical Sociology, 32, 649-673. https://doi.org/10.1163/156916306779155199

[10] Jindra, M. (2014) The Dilemma of Equality and Diversity. Current Anthropology, 55, 316-334. https://doi.org/10.1086/676457

[11] Ritzer, G. (2008) Modern Sociological Theory. Fourth Edition, McGraw-Hill, New York, New York. 
[12] Dahrendorf, R. (1959) Class and Class Conflict in Industrial Society. Stanford University Press, Stanford, California.

[13] Murphy, R. (1988) Social Closure: The Theory of Monopolization and Exclusion. Clarendon Press, New York.

[14] Jackson, F.L. and Leon, R.A. (2010) Enlarging Our Understanding of Glass Ceiling Effects with Social Closure Theory in Higher Education. Higher Education: Handbook of Theory and Research, 25, 351-379.

[15] Alba, R. and Nee, V. (2003) Remaking the American Mainstream: Assimilation and Contemporary Immigration. Harvard Press, Cambridge, Massachusetts. https://doi.org/10.4159/9780674020115

[16] Smith, T.W., Marsden, P.V. and Hout, M. (2016) General Social Surveys (GSS), 1972-2016 [Machine-Readable Data File]. National Opinion Research Center, 2005 (Producer), Chicago, IL; The Roper Center for Public Opinion Research, University of Connecticut (Distributor), Storrs, CT. 